\title{
A cultura do medo e o desviante no Jornal do Almoço: ponderações sobre os espectadores de Rio Grande (RS)
}

\author{
Culture of Fear and the Deviant in Jornal do \\ Almoço: Weighings on the Spectators from Rio \\ Grande (RS)
}

\author{
Carolina Borges Gonçalves ${ }^{1}$ \\ Michele Negrini ${ }^{2}$
}

DOI: $10.19177 /$ memorare.v8e12021286-303

\begin{abstract}
Resumo: 0 presente trabalho tem como objetivo analisar o papel do Jornal do Almoço na construção da cultura do medo e a percepção dos espectadores de Rio Grande sobre a imagem do desviante adotada pelo veículo. Para a realização da pesquisa, foram realizadas entrevistas semiestruturadas, em amostragem aleatória entre dez espectadores do Jornal do Almoço, residentes em Rio Grande. Esta pesquisa debruçou-se, principalmente, sobre as ideias de Martín-Barbero (1998; 2004), Becker (1963), Pastana (2005) e outros teóricos relevantes para traçar um sentido de estruturação dos conceitos-chave.

Palavras-chave: Cultura do medo; Desviante; Violência; Jornal do Almoço; Telejornalismo.
\end{abstract}

\begin{abstract}
The present essay aims to analyze the role of Jornal do Almoço in the construction of the culture of fear and the perception of spectators from Rio Grande about the image of the deviant embraced by the vehicle. To carry out the research, semi-structured interviews were conducted, in a random sampling between ten spectators of Jornal do Almoço living in Rio Grande. This research leaned on, mainly, on the ideas of Martín-Barbero (1998; 2004),

Becker (1963), Pastana (2005) and other relevant theorists to trace a sense of structuring of the key concepts.

Keywords: Culture of Fear; Deviant; Violence; Jornal do Almoço;

Telejournalism.
\end{abstract}

\footnotetext{
1 Jornalista pela Universidade Federal de Pelotas. E-mail: carolinab.goncalves@hotmail.com.

2 Orientadora do Trabalho. Doutora em Comunicação pela PUC-RS. Tem pós-doutorado pela Universidade Federal da Bahia (UFBA), no programa de pós-graduação em Comunicação e Cultura Contemporâneas. Professora da Universidade Federal de Pelotas (UFPel). Integrante do núcleo de pesquisadores do Grupo Interinstitucional de Pesquisa em Telejornalismo (GIPTele). E-mail: mmnegrini@yahoo.com.br
} 


\section{Perspectivas introdutórias}

Medo de assaltos, medo de sair à noite, medo de outras pessoas.

Esses são alguns dos receios comuns entre aqueles que estão assustados com a tão temida e crescente insegurança social. E esse grupo de preocupados com a questão também cresce e acessa mais e mais medidas para garantir a proteção desejada. A televisão, muitas vezes, com a força de suas imagens e os recortes de crimes e infrações colocados dia a dia na programação, mantém o padrão de que a criminalidade tem tomando grandes proporções.

Nesse sentido, propõe-se trazer reflexões acerca da construção de uma cultura do medo através das notícias de violência cotidiana apresentadas pelo Jornal do Almoço, da RBS TV, nosso objeto de estudo. Nos propomos a pensar, também, na imagem do desviante neste telejornal, para observar se existe algum padrão na personificação de quem se deve temer.

O Jornal do Almoço está no ar desde 1972, sendo o telejornal mais antigo da RBS TV, emissora afiliada da Rede Globo. 0 jornal apresenta assuntos diversos como variedades, cultura, noticiário factual, esportes, entrevistas, etc. É um programa de grande audiência, tendo ficado em primeiro lugar nas pesquisas entre os telejornais locais mais lembrados no Top of Mind, promovido pela revista Amanhã, em 2013. Desde o início, o Jornal do Almoço propõe uma linguagem mais leve, principalmente por ser o pioneiro em apresentação jornalística no horário de almoço. A partir de 2010, o jornal modificou seu formato (GUEDIN e CRUZ, 2014), passando a incorporar características que diferem ainda mais do padrão de telejornalismo tradicional, com apresentadores de pé, descontração e informalidade na exibição e até mesmo com o próprio apresentador dando algum tipo de parecer sobre a notícia.

Essas mudanças reforçam a criação de uma relação mais próxima do espectador, fato perceptível tanto pelas técnicas utilizadas no telejornal, quanto pelos discursos dos apresentadores, que se referem ao espectador de forma direta. Para Silva (2013), o JA se configura como programa de entretenimento, gênero revista, pois mantém formatos como telejornalismo, quadros humorísticos, reportagens, música, etc. e, assim, continua se mantendo na liderança do meio-dia no estado, desde a sua fundação. (SILVA, 2013) . Mesmo tendo um formato bastante voltado à informalidade, violência e morte também fazem parte da pauta do programa, o que dá bases para a realização deste estudo.

Cabe destacar que outras áreas, como o direito e a assistência social, têm debatido a temática da cultura do medo pensando na sua relevância para a composição do cenário social, suas implicações nas transformações sofridas no cenário urbano, nas formas de segregação que surgem a partir da resistência das pessoas umas às outras. Alguns dos estudos voltados a esta temática colocam a mídia entre os responsáveis por estruturar este processo.

Apesar de o jornalismo ser apontado como um dos agentes na disseminação da cultura do medo, há pouco interesse da área de 
comunicação no tema ${ }^{3}$. Considerando a presença dos meios de comunicação, e visto os impactos sociais que geram a cultura do medo, é pertinente repensar o fazer jornalístico, propondo um pensamento mais complexo com relação à temática da violência, que suscite compreensões mais aprofundadas sobre o assunto permitindo, assim, pensar em soluções mais eficazes ao problema.

Para desenvolver este estudo, além da apresentação de reflexões teóricas, realizou-se entrevistas semiestruturadas com espectadores deste telejornal, na intenção de obter uma perspectiva da visão do público sobre o assunto. Para isso, utilizamos uma amostra de dez espectadores selecionados de forma aleatória, adotando como único critério que residissem em Rio Grande (RS) e consumissem o Jornal do Almoço. Essa postura foi adotada para que já houvesse uma identificação com o telejornal e para que não fosse necessário selecionar matérias para mostrar aos entrevistados, o que poderia deixar o estudo tendencioso. Fizemos um roteiro de dez perguntas, formuladas de forma a cercar o assunto, não abordá-lo diretamente, também no intuito de captar as percepções dos respondentes de forma natural, relacionandoas ao seu cotidiano. Também foi aplicado um questionário socioeconômico, com perguntas fechadas, para obter algumas informações a respeito do contexto dos participantes.

\section{Mídia e cultura do medo}

Para falarmos sobre mídia e cultura do medo, cabe começar fazendo reflexões sobre violência. Definir violência, em um primeiro momento, parece remeter-se a agressões físicas, verbais, ou outra ação que seja tomada contra algo ou alguém de forma clara e objetiva. É comum, principalmente nos meios de comunicação, tratar e discutir a violência apenas do ponto de vista da violência urbana. Roubos, ataques, homicídios, tráfico de drogas e outras ações que acometem este cenário costumam ser pautas bastante especuladas nos noticiários. Essas ações, por vezes, são retratadas de modo que se isolam na perspectiva de um fato fechado em si mesmo, como se não fosse dotado de um contexto, não só do ponto de vista da história do sujeito, mas, principalmente, sobre o contexto estrutural que permite pensar as correlações da violência que chega ao ato. Para conceituar a violência no modo como abordaremos neste trabalho, optou-se por utilizar as reflexões de Chauí (2011, 2013) numa primeira abordagem da temática.

Para Chauí (2011), a violência é uma oposição à ética, pois quebra os valores a ela atribuídos. Nesse caso, desconsiderar um sujeito enquanto ser "racional, livre e responsável" (p. 379) e coisificá-lo, ignorando atributos da "razão, vontade, liberdade e responsabilidade" (p. 379) aos quais todos são dotados se configura como ação violenta. Portanto, a violência pode se valer de meios mais sutis para ir contra a natureza de alguém. Como exemplo disso, a autora salienta: "O direito à liberdade encontra os obstáculos impostos pela desigualdade econômica, social, cultural e política e pela privatização da informação

\footnotetext{
${ }^{3}$ Consultamos mecanismos de busca especializados, como site da CAPES, e não encontramos uma amplitude de pesquisas relacionadas ao tema na área de comunicação.
} 
pelos oligopólios que dominam os meios de comunicação." (CHAUÍ, 2013, p. 154)

Dessa maneira, é ilustrada a violência estrutural a qual muitos sujeitos estão submetidos todos os dias. Portanto, entende-se a violência para além da criminalidade e a segunda pode ser reflexo da primeira. A autora reflete a respeito dos mecanismos que produzem a exclusão e mascaram a violência estrutural que se mantém no Brasil. Essa diferenciação que distingue um 'eu não violento' do 'ele violento' dá margem ao pensamento excludente que permite "determinar" os agentes violentos e legitimar ações de limpeza social, por exemplo.

Essa diferenciação é uma das principais questões apontadas por Becker (1963) na caracterização daquele que é julgado como desviante. Para o autor, o desviante não é definido propriamente por suas ações, mas pelo julgamento que fazem dele e, é importante salientar, em diferentes grupos, que atos podem ou não ser admitidos como de desvio. Portanto, temos uma diferenciação no julgamento de desvio a partir de grupos distintos.

É comum que na mídia sejam apresentados, inclusive, como fator central dos noticiários, fatos relacionados à violência. É importe destacar que a violência tratada nos noticiários não é pensada enquanto estrutura, mas, frequentemente, restrita aos atos contra algo ou alguém e que essa violência é vista a partir da quebra da norma, principalmente, do ponto de vista legal. Salienta-se essa parte, principalmente, porque certos tipos de violência podem ganham mais espaço, mais legitimidade, e até mais severidade em detrimento de outras. Nesse caso, pode-se ter como exemplo ações violentas em resposta a uma violência anterior, que são comumente justificadas e apontadas como legítimas.

Como aponta Becker (1963), regras formais, mesmo que consolidadas, podem diferir das que são consideradas apropriadas para a maioria da população. Mesmo que uma agressão em resposta a outra também possa se caracterizar como uma violação de norma, do ponto de vista legal, ela é acatada como uma ação legítima. Ainda segundo o autor (1963, p.26):

O mesmo comportamento pode ser uma infração das regras num momento e não em outro; pode ser uma infração quando cometido por uma pessoa, mas não quando cometido por outra; algumas regras são infringidas com impunidade, outras não. Em suma, se um dado ato é desviante ou não, depende em parte da natureza do ato (isto é, se ele viola ou não alguma regra) e em parte do que outras pessoas fazem acerca dele.

Nesse caso, o desviante é classificado de acordo com grupos específicos e, ao retratar o sujeito, enquanto desviante, a mídia adota a classificação de um determinado grupo. Assim, podemos pensar nas problemáticas que podem surgir, a partir das representações relacionadas a essa questão, bem como que tipo de atenção a mídia dispõe para certos atores sociais quando a pauta é violência.

Rondelli (1998) aponta que os episódios da violência cotidiana não têm a elaboração, sagacidade, glamourização adotadas em casos de serial killers ou personagens de ficção, ou ainda uma razão ideológica como a dos terroristas. Ao contrário, estas ações são retratadas com a maneira bruta que se expressam e a ausência de "mediações institucionais" (RONDELLI, 1998, p. 147) e mostram tanto o isolamento 
social dos envolvidos quanto a "impotência da sociedade em resolver seus conflitos” (RONDELLI, 1998, p. 148).

Pensando na abordagem de violência cotidiana, vale apontar a sua presença nas notícias que aparecem com frequência, apresentadas de forma factual. Destas notícias, muitas são abordadas sem uma contextualização mais ampla, como se observas em pautas relacionadas aos assaltos e ao tráfico de drogas. Considerando Becker (1963), o desvio se constrói a partir da imposição, através de processos políticos, dos componentes encarados como "normais" por determinados grupos. Através desta imposição, os conceitos de normatização são legitimados. Portanto, o desvio (e, por consequência, o desviante) não se caracteriza, necessariamente, sobre o ato praticado, mas pelos processos de julgamento e reação que surgem a partir dele. Ao mesmo tempo, a pessoa que passa a ser julgada pode não acatar essa opinião. Portanto, o rótulo ao qual o desviante é submetido está relacionado ao grupo social em que está inserido. Pensando na sociedade como um todo, seu pacto social gira em torno da ideologia dominante que, como aponta Kellner (2002, p. 83), geralmente recai sobre o "branco masculino, ocidental, da classe média ou superior." Ainda segundo o autor, "raças, classes, grupos e sexos diferentes" são considerados secundários e até inferiores.

Esse conjunto de desvios pode ser encarado como a personificação daquele a quem se deve temer, resultando numa cultura do medo que altera o ambiente urbano e as relações humanas. Sendo assim, "a incerteza e a desconfiança que nos produz o outro, qualquer outro étnico, social, sexual - que se aproxima de nós na rua é compulsivamente percebido como ameaça" (MARTÍN-BARBERO, 2004, p. 295).

Para Pastana (2005), o medo generalizado que se criou no em torno de crimes é uma preocupação ainda mais pungente que a própria violência. Segundo a autora, a somatória da criminalidade associada ao medo altera os hábitos e comportamentos modificando, também, a composição das cidades. Nesse sentido, essas combinações passam a criar barreiras reais entre os indivíduos - com uma arquitetura voltada aos muros, às cercas e à sistemas mais modernos de segurança, além do crescimento de empresas de vigilância e a circulação de armas de fogo. Outros autores como Mia Couto (2011), em discurso na Conferência do Estoril, atentam para os interesses econômicos e o controle social por trás da construção e disseminação do medo.

Diante desta lógica, na qual os indivíduos tendem a modificar seus comportamentos, em virtude da convivência com o medo, Pastana (2005, p.183) traça uma definição para o que seria a cultura do medo:

Representa a somatória dos valores, comportamentos e do senso comum que, associados à questão da criminalidade, reproduz a ideia hegemônica de insegurança e, com isso, perpetua uma forma de dominação marcada pelo autoritarismo e pela rejeição dos princípios democráticos .

Desse modo, verifica-se que o comportamento associado à ideia da personificação do agente violento, é um fator relevante para perpetuar a segregação social e, para compreendê-lo, é necessário pensar as questões estruturais que o envolvem, incluindo a circulação de bens simbólicos apresentada pela mídia. Para Martín-Barbero (1998, p. 4), 
não podemos compreender o sentido e a envergadura dos novos medos relacionando-os unicamente com o aumento da violência, da criminalidade e da insegurança das ruas. Pois os medos são chave dos novos modos de habitar e comunicar, são expressão de uma angústia mais profunda, de uma angústia cultural.

Essa angústia cultural, geradora do medo e do estranhamento ao outro, significa a perda do referencial, agravada pelos processos de globalização, aos quais a mídia e seus novos e abrangentes modos de comunicação fazem parte e, como coloca Bauman (1999, p. 102): “Amplamente notada e cada vez mais preocupante, a polarização do mundo e de sua população não é uma interferência externa, estranha, perturbadora, um entrave ao processo de globalização - é efeito dele"; a exemplo de tentativas de homogeneização da vida. Nesse aspecto, Martín-Barbero (1998, p. 6) salienta que:
Nas ruas, torna-se suspeito todo aquele que traduz um gesto que não podemos decifrar em vinte segundos. E eu me pergunto se esse outro, convertido cotidianamente em ameaça, não tem muito a ver com o que está acontecendo com a nossa cultura política, com o crescimento da intolerância, com a impossibilidade desse pacto social de que tanto se fala, isto é, com a dificuldade de reconhecer-me na diferença do que o outro pensa, no que o outro gosta e no que o outro tem como horizonte vital, estético ou político.

Face às perspectivas abarcadas é que pensamos a cultura do medo e suas implicações. A partir do estranhamento que nos causa o outro, que medidas tomamos que agravam a situação de distanciamento entre os sujeitos? Esse distanciamento, que se acentua nos modos de viver atuais - como os condomínios, os espaços fechados para convívio, a cidade voltada para o fluxo e não para o encontro (MARTÍN-BARBERO, 1998) - aponta para uma nova dinâmica e para a possibilidade de uma segregação ainda maior dentro da sociedade. Para Bauman (1999, p. 29):

As elites escolheram o isolamento e pagam por ele prodigamente e de boa vontade. 0 resto da população se vê afastado e forçado a pagar o pesado preço cultural, psicológico e político do seu novo isolamento. (...) São pura e simplesmente postos para 'fora da cerca' sem que se pergunte a sua opinião, têm o acesso barrado aos 'comuns' de ontem, são presos, desviados e levam um choque curto e grosso quando perambulam às tontas fora dos seus limites, sem notar os sinais indicadores de 'propriedade privada' ou sem perceber o significado de indicações não verbalizadas mas nem por isso menos decididas de 'não ultrapasse'."

Pensando nisso, é preciso atentar que aqueles que não detêm das mesmas condições para utilizar as estratégias de proteção, sofrem com os processos de segregação e, também, com mudanças de sua cultura e de seu modo de viver, o que pode se configurar como um processo doloroso e violento para estes sujeitos.

\section{Perspectivas metodológicas e analíticas}

Para o desenvolvimento deste trabalho, optou-se pela realização de pesquisa exploratória com a realização de entrevistas semiestruturadas. Para Marconi e Lakatos (2003) a pesquisa exploratória consiste em “investigações de pesquisa empírica cujo objetivo é a formulação de questões ou de um problema, com tripla finalidade: desenvolver 
hipóteses, aumentar a familiaridade do pesquisador com um ambiente, fato ou fenômeno, para a realização de uma pesquisa futura mais precisa ou modificar ou clarificar conceitos." (2003, p. 189). Segundo as autoras, podem-se empregar procedimentos sistemáticos para observações empíricas ou análise de dados, ou, ainda, as duas ao mesmo tempo. Pode-se obter descrições qualitativas ou quantitativas e deve-se "conceituar as inter-relações ente as propriedades do fenômeno, fato ou ambiente observado" (2003, p. 189). Visto os objetivos da pesquisa já mencionados no decorrer do trabalho, encaixamos a pesquisa como caráter exploratório.

Para Manzini (1991), a entrevista semiestruturada é realizada através de um roteiro de perguntas voltadas a uma temática, mas que garante ao pesquisador autonomia para captar outras informações que possam ser analisadas no decorrer da entrevista. Segundo o autor, a entrevista semiestruturada permite uma liberdade mais ampla no surgimento dos tópicos da entrevista, além das respostas não estarem restritas a um padrão de alternativas.

Tendo em vista o interesse do estudo em se aprofundar nas percepções dos telespectadores do Jornal do Almoço, a escolha deste método se justifica por ele não levar ao engessamento da pesquisa, mas manter um padrão em que todos os entrevistados respondam a, pelo menos, uma mesma estrutura de perguntas, que permitem dados mais precisos sobre a impressão dos respondentes.

Para tanto, elaborou-se um questionário com perguntas abertas, composto por dez questões relacionadas ao uso da televisão e as percepções dos entrevistados acerca do objeto delimitado, a relação deles com pautas relacionadas à violência, suas reações a elas e suas percepções acerca da abordagem do veículo em questão. As perguntas foram elaboradas de forma aberta, na intenção de não constranger ou induzir respostas aos entrevistados. Optou-se por construir as perguntas de maneira que os objetivos fossem apresentados de maneira mais sutil, permitindo, através das respostas dos entrevistados, captar elementos que dessem significado aos comportamentos e impressões dos respondentes.

A pesquisa também fez uso de questionário socioeconômicocultural, com perguntas fechadas, que foram entregues no momento de cada entrevista. Esse questionário foi aplicado para que tivéssemos acesso a outras informações dos entrevistados que pudessem ser correlacionadas com as informações obtidas por meio das entrevistas.

Como critério, optou-se por aplicar a pesquisa com pessoas que assistissem ao Jornal do Almoço no seu cotidiano para que, além de acompanharem o formato editorial do programa, também houvesse mais chances de identificação com o jornal.

A pesquisa foi aplicada num universo de 10 pessoas, por entender que, como aponta Orozco (1998), em um universo de 10 a 25 entrevistados, as respostas atingem um nível de saturação. Além disso, foi critério da pesquisa que os entrevistados residissem em Rio Grande, com amostragem aleatória4. Sendo assim, as entrevistas foram

\footnotetext{
${ }^{4}$ A amostragem aleatória foi composta por pessoas voluntárias, residentes em Rio Grande e que são espectadoras do programa Jornal do Almoço.
} 
realizadas em variedade de gênero, idade, escolaridade e renda, com flexibilidade no roteiro para que fossem aproveitadas as particularidades de cada indivíduo, utilizando estímulo a respostas completas dos entrevistados (GIL, 2008).

A renda média dos entrevistados diverge entre as opções: um a dois e dez a quinze salários mínimos. É importante salientar que um dos entrevistados, o Dez, é formado em Comunicação Social na Universidade Católica de Pelotas, com habilitação em Jornalismo. Esse é o único dado relacionado à identidade dos respondentes que será revelado, por ser uma informação relevante na interpretação da pesquisa, no sentido de que este respondente teve ferramentas, na sua formação, para ter uma visão mais ampla sobre o jornalismo e a construção das notícias.

\subsection{Quem estrutura a cultura do medo?}

Para identificarmos questões referentes à cultura do medo, optamos por trazer algumas questões de prevenção à violência que fossem tomadas pelos sujeitos. Isso nos permitiu observar de maneira que as pessoas se privavam de uma socialidade com outros indivíduos e com o espaço urbano, que possibilitou refletir sobre questões de segregação, além de observar o papel midiático na estruturação desse processo. A primeira observação relevante diz respeito às ações realizadas pelos entrevistados, com o intuito de se prevenir de possíveis ações violentas. Ações, inclusive, em que os entrevistados ao menos demonstrassem interesse em mencionar, por estarem tão incorporadas ao seu cotidiano.

Na verdade, nem dá pra considerar que eu tomo muitos cuidados. Eu tenho uma rotina onde eu frequento alguns lugares e eu não percebo muito a violência nesses lugares. Isso, acho que pelo fato de que me locomovo de carro, então eu saio dos lugares e já vou pra outros. No meu trabalho eu acabo não saindo tão tarde quanto eu gostaria justamente pra evitar isso. (...) Não dá pra considerar que sou uma pessoa que toma muitos cuidados com a segurança. Claro, normal: olhar pro lado pra ver se não está vindo alguém, quando saio que não é de carro saio sem nada." (Entrevistado Três)

Andar sempre em local movimentado, onde tem bastante de gente, andar sempre com alguém e procurar não andar muito tarde, por mais que eu ande, muitas vezes, fico me cuidando na rua. P: Como tu faz pra te cuidar na rua? Eu ando normalmente em rua contramão, que aí eu vejo o cara pela frente [por causa dos assaltos de moto], que aí o cara vem, eu vejo que ele tá parando; ou se vem vindo alguém na minha frente eu vejo se atravessa a rua ou algo assim, normal, instinto normal." (Entrevistado Oito)

Outro fator relevante a destacar é que nenhum dos entrevistados se identificou como agente excluído no processo de prevenção à violência, embora o Entrevistado Três tenha mostrado reflexões sobre o assunto:

Eu não estou tão sujeita [a certos tipos de violência] porque eu não sou o perfil que é parado na rua. Já vi acontecer isso com outras pessoas e elas serem tratadas muito mal, mas eu não tenho esse estereótipo e eu tenho consciência disso. Eu nunca fui parada, então acho que dificilmente eu sofreria uma violência da polícia, por exemplo, que é uma das violências que eu vejo. (...) P: Que estereótipos tu achas que são esses? Primeiro homem, negro, se eu andasse circulando a pé. Eu não me encaixo no perfil que a polícia para na rua, nem em blitz eu nunca fui parada. 
Percebemos, de acordo com o entrevistado, a existência de um padrão de conduta em que não somente esse sujeito pode tentar proteger-se da violência, mas ele pode ser o foco dessa própria proteção. Essas atitudes configuram violência não só porque "coisificam" o sujeito (CHAUÍ, 2013), mas também porque retiram deles a escolha (BAUMAN, 1998). Como mencionado pelo Entrevistado Dois: "Não costumo tomar cuidados. Claro, evito sair de madrugada, mas se tiver que sair, saio. Procuro andar sempre acompanhada. Não ando com dinheiro na bolsa". Atentamos para a frase "se tiver que sair, saio", porque ela demonstra, também, essa ausência de escolha.

Em um primeiro momento pode-se pensar que, basicamente, o respondente não sai porque não tem medo. Porém, propomos refletir sobre outras questões do seu contexto. 0 Entrevistado Dois tem renda mensal de um a dois salários mínimos, não tem carro e vive sozinho. Ainda que o respondente se preocupe com a segurança, em determinado momento, o entrevistado demonstra não deter opções de escolha, que permita-o adotar ações mais seguras, como observado por outros entrevistados. Diante desta situação, o sujeito se coloca em uma situação diferente de outros respondentes que, como mencionaremos mais adiante, podem traçar estratégias que suportem seu isolamento em nome da sua segurança. A situação do Entrevistado Dois é semelhante à situação mostrada no Entrevistado Oito, que chega em casa todos os dias às 23 h, sozinho, mas não há uma escolha de tornar sua situação mais confortável.

As prevenções tomadas para evitar as situações de violência colocam os sujeitos - de um modo geral, porque essas respostas aparecem de forma bastante clara - em formas bastante restritas de experiência:

Tomo muitos cuidados. Eu nunca saio de casa com bolsa, com o celular na mão. Se eu tenho que ir pro centro pagar conta eu sempre levo só o cartão no bolso e deu. Tento sair o mais discreta possível, sem nada. Eu só saio de relógio porque eu penso que se alguém quiser me roubar eu tenho que ter alguma coisa pra dar. Então eu penso: 'não, vou sair de relógio e só', sabe? A não ser que eu vá de táxi ou de carona e vá ir e voltar de carona, que eu sei que eu vou estar dentro do carro. Segura." (Entrevistado Um)

Saio muito pouco de casa. Por exemplo, pra sair da casa do Douglas pra vir pra cá pra casa, que é perto, a gente vem com o cachorro pra segurança um pouquinho maior. Mas, fora isso, eu evito ir a muitos lugares por causa da segurança, por exemplo, sair de noite com a moto eu não gosto porque podem roubar minha moto. Eu evito viver. (...) Antes, eu achava que era no sentido de que aconteceu só com ele, não vai acontecer comigo. Mas agora, com a repercussão eu fico mais neurótica. (Entrevistado Quatro)

Diante dos trechos apresentados, fica evidente, nas conversas, que a mídia não se constitui como único fator preponderante que permite aos entrevistados pensarem a violência ou criarem um medo em função dela. Em diversas entrevistas o telejornal apareceu como um fator que dá credibilidade ao fato, no sentido de que se apareceu no jornal, é sério. Quando a tevê se ausenta da informação, fica um vazio de referencial (VIZEU, 2006). "[Sobre a reflexão da violência a partir dos fatos noticiados pelo Jornal do Almoço] A gente diz que não, mas tu vês um assalto entrando numa garagem, tu fica mais te orientando sobre essas coisas. Reflete bastante" (Entrevistado Cinco). 
Tem gente que até acaba criando transtornos de ansiedade, de pânico em função das matérias. Eu tive isso também, eu não saía mais de casa a pé, porque eu tinha medo de ser assaltada em qualquer lugar que eu fosse, eu tinha medo das pessoas, porque eu via isso no jornal. E não era essa a realidade de Rio Grande. (Entrevistado Um)

O entrevistado relatou que, a partir daí, parou completamente de assistir a todos os telejornais. Voltou a ver posteriormente, de maneira recorrente.

Agora eu consigo ver com a ciência de que não é tudo aquilo que a tevê está passando, que aquilo é meio ilusório. (...) Teve uma vez, por exemplo, que tinha um estuprador no Cassino e ele desligava o disjuntor da casa das pessoas. Um dia faltou luz aqui em casa e eu me tranquei no quarto e chorava, porque eu achava que ele estava aqui na frente da minha casa. Isso, querendo ou não, em função da mídia, da repercussão que isso acaba tendo. (Entrevistado Um)

Como se observa, em alguns casos, o medo se torna um terror psicológico. Altera a dinâmica das pessoas e da cidade, o que se caracteriza como uma cultura do medo. Nessa perspectiva, podemos observar que a exposição excessiva - e de caráter meramente expositivo dos fatos violentos, contribui para essas alterações no cenário social. 0 Entrevistado Dez apontou algumas reflexões entre a mídia e a estruturação destes comportamentos:

Eu acho que, de modo geral, quando a tevê flagra alguma coisa, a imagem é muito forte. Aí tu juntas a imagem com uma sensação de medo da população, com apresentador ou apresentadores que fazem os seus comentários, que passam a ideia de 'bom, estamos certos' e vai somando todos esses pontos e tu crias um caldo de cultura para que as pessoas sintam, primeiro: que estejam permanentemente com medo. Segundo: se sintam no direito de julgar, sem dar direito a defesa, e de agir também, o que é o pior. Isso é um perigo muito grande, acho que nós estamos num momento muito perigoso e acho que os meios de comunicação tem uma responsabilidade muito grande nisso, mas não estou vendo mudar (Entrevistado Dez)

Em nosso modo de ver, é possível verificar uma cultura de medo sendo reconhecida pelos próprios entrevistados. Ao entenderem os riscos que constituem os seus contextos sociais, eles atribuem esta cultura a três formas comunicacionais: telejornais, internet e conversa entre pessoas. "[Por que se interessa nas pautas de segurança] Saber o nível de segurança da minha cidade e saber onde não frequentar. $P$ : $E$ tu achas que o local onde vives é violento? Muito, e cada vez mais. P: Como tu percebes isso? Pelas notícias e pelas redes sociais" (Entrevistado Quatro). 0 entrevistado relata não ir a lugares caracterizados pelo público como sendo perigosos.

[Sobre a violência na cidade] Acho que tem problemas violentos, tem locais ou horários. Mas eu acho muito forte essa coisa de dizer o lugar onde eu vivo é violento. Um lugar violento pra mim é um lugar de guerra, né? E eu acho que a gente está muito longe disso, embora as vezes tenha essa impressão, parece, pelo que dizem as notícias as vezes, pela forma, até o apresentador. Uma coisa que me incomoda é a apresentadora do JA (...) ela já faz uma cara, assim, que me incomoda, porque parece que ela tá avisando: vou chamar sangue. Eu não gosto disso. Essa é a parte que eu não gosto, do sangue pelo sangue. Acho que tem que estar linkado a políticas públicas, a orientações a população. $P$ : A palavra violência, pra ti, 
não necessariamente está ligada a essas questões mais pontuais que aparecem no Jornal, ela carrega... A palavra violência carrega uma coisa muito mais forte, como se carregasse uma sequência disso [de violência] que não vai terminar, que não tem o que fazer, né? E que a gente tem que se encerrar em casa. Isso é ruim. (Entrevistado Dez)

A partir das ponderações do entrevistado, cabe inferir que a falta de reflexão das condições estruturais de violência no telejornal permite pensar numa maldade individual, na responsabilização individual - que pode ser danosa para pensar em soluções realmente eficazes para o problema. Dessa maneira, se a violência é característica e responsabilidade individual, a lógica é que se imagine que ao eliminar ou excluir estes agentes do convívio seja o suficiente para manter uma convivência pacífica. Considerando esses efeitos e a participação da mídia na construção desse imaginário, é preciso refletir sobre o que e como deixamos disponíveis as informações que serão decodificadas pelos receptores.

\subsection{Desviante para quem?}

Para tratar da questão do desviante, optou-se por não questionar diretamente, para que as pessoas não se sentissem dirigidas ou constrangidas em responder as perguntas. Dessa forma, assumiu-se um risco de não obter as respostas com a mesma clareza, mas os entrevistados deixaram inúmeros pontos a serem interpretados ao longo de suas falas. Os padrões e formas de desvio considerados por cada um foram surgindo em seus discursos, envolvidos nas respostas dadas a diversas perguntas. Em relação a um possível padrão de notícias, no entanto, apontaram uma visão generalizada em relação a um comportamento de "prevenção" ou agentes que possam se caracterizar "suspeitos".

Em outras circunstâncias, no entanto, a personificação do desvio se mostrou com bastante ênfase. Nota-se que, aqui, que o desviante é percebido muito menos por sua ação, e muito mais pelas marcas que traz no próprio corpo. Percebe-se que a violência sai do sujeito que desconfia da violência do outro e passa a ser empregado no sujeito considerado suspeito, pois, retira dele a possibilidade de uma sociabilidade comum a todos (CHAUÍ, 2013). Essa exclusão gera outras desigualdades e se caracteriza, portanto, como forma de segregação, mesmo que velada.

[Sobre ações tomadas para evitar a violência] P: Como tu consegues identificar se tem alguém suspeito? Quais são os teus critérios de avaliação? Isso chega até a ser meio preconceituoso, mas geralmente é um cara negro, com capuz enterrado na cara, um boné enterrado na cara, também meio espiado [se cuidando], olhando pra trás, tipo: ele te vê e ele olha pros lados, se liga na volta e tu já pensa: esse cara tá cuidando se tem algum risco de me assaltar. Um cara mal vestido, todo rasgado, geralmente de moletom largo, sabe? Onde ele pode esconder alguma coisa. É o que mais me deixa preocupado. (Entrevistado Sete)

De acordo com a fala do entrevistado, percebe-se que a primeira característica adotada para detectar um indivíduo suspeito é a cor da pele. Nas outras características, ele tenta atribuir um sentido, mas "negro" é pré-reflexivo. Ele não menciona o porquê "negro". 0 sujeito atribui o termo "negro" a um padrão de comportamento, porém, sabe-se 
que essa proposição não se sustenta, visto que "negro" não se configura como um comportamento. Sendo assim, o seu ponto de vista torna a questão mais intimamente relacionada ao corpo, aquilo que o sujeito, de fato, é. Ao mesmo tempo, o entrevistado classifica seu critério de seleção como "meio preconceituoso". Vale ressaltar que negar o preconceito não permite desconstruí-lo e "a sociedade não percebe que as próprias explicações oferecidas são violentas, porque está cega ao lugar efetivo de produção da violência, isto é, a estrutura da sociedade brasileira" (CHAUÍ, 2011, p. 383).

Algumas dessas características são reconhecidas pelo Entrevistado Três, ao relatar a abordagem policial e, consequentemente, outras questões trazidas ao espaço midiático:

Eu não sou o perfil que é parado na rua. Já vi acontecer isso com outras pessoas e elas serem tratadas muito mal, mas eu não tenho esse estereótipo e eu tenho consciência disso. Eu nunca fui parada, então acho que dificilmente eu sofreria uma violência da polícia, por exemplo, que é uma das violências que eu vejo P: Que estereótipos tu achas que são esses? Primeiro homem, negro, se eu andasse circulando a pé. Eu não me encaixo no perfil que a polícia para na rua, nem em blitz eu nunca fui parada. [Sobre opinião no Jornal do Almoço] Sempre tem opinião. Falando na relação da segurança sim, até na forma com que se fala, as palavras que se usam. Eu acho que se passa a mão por cima da violência da polícia, [falam que] são atos de vandalismo, são atos de terrorismo, são invasões, se for de classe mais baixa ou de qualquer movimento social. Eu acho que isso tem a ver com a forma política que a mídia se posiciona. Ela diz que não é nada, mas ela sempre é alguma coisa. E eu acho que nas pautas de violência ela é assim, sim. (Entrevistado Três)

O entrevistado percebe um estigma nas ações do Estado e na mídia, considerando, portanto, os atores descritos como desviantes do ponto de vista social. Como destacado pelo entrevistado, as expressões "homem, negro, que anda a pé", é observada como aquele sujeito que sofre com ações policiais, e classes baixas e movimentos sociais são tidos como estigmatizados pela mídia. Cabe destacar que há complexidades na realização de definições acerca de classe social, mas o dado apresentado pelo entrevistado nos apresenta muitas problemáticas no que diz respeito à abordagem midiática que, segundo ele, não está a serviço de todos. Além disso, o entrevistado se mostrou incomodado com um posicionamento existente dentro do produto midiático, mas que não é assim mostrado. 0 Entrevistado Dez aponta:

[Sobre opinião] Eu acho que sim. Porque hoje os apresentadores, de modo geral e no Jornal do Almoço, específico também, eles fazem caras e bocas, já dizendo, já mostrando aquilo que ele quer deixar claro (...) Então eu não tenho direito de pensar naquilo, eles dão a notícia e dão o comentário. P: Tu nota algum padrão? Tem o padrão da opinião deles de que, como a gente estava falando, se tem um fato marcante sobre o qual eles estão falando, é aquela questão: 'que coisa horrível! Que isso tem que mudar!' Tudo bem, a gente sabe, todo mundo sabe que tem que mudar. Agora cada pessoa dentro dessa sociedade tem que achar um jeito de mudar, e a sociedade tem que mudar no coletivo. Não vai ser um comentário da apresentadora do Jornal do Almoço que vai dizer como a sociedade deve mudar. A sociedade deve pensar coletivamente. Então é um padrão, primeiro: de dirigir esse pensamento e essa reflexão, né? Ou até evitar essa reflexão, no momento em que dão a sua ideia. Segundo: tem bastante manutenção de status quo, quer dizer: tá assim, a gente tem que mudar, mas no restante da programação não tem nada que leve a sociedade a

Memorare, Tubarão, v. 8, n. 1, jan./jun. 2021. ISSN: 2358-0593 
refletir. Assim como o próprio racismo, que a gente estava falando, que é a sociedade que tem que se manifestar que tem que mudar. Mas a sociedade não vai mudar se não mudar a desigualdade no meio dela, mas quando se fala em mudar, de redução a essa desigualdade, quem é que reflete sobre ela? Não reflete. E se alguém fala em redução da desigualdade já é taxado disso e daquilo, de baderneiro, disso e daquilo outro. Eles não levam a reflexão pra mudar efetivamente. (Entrevistado Dez)

Essa questão das "caras e bocas", comentada pelo Entrevistado Dez, é muitas vezes percebida como uma forma de reação natural pelos espectadores. Essa "reação natural", sem ser dita como posicionamento, pode dificultar outras percepções do fato, ou podemos pensar que o espectador a coloca como natural por se identificar com aquele posicionamento. "Nas [pautas] de violência não noto tanto [um posicionamento] porque acho que gera uma indignação até deles." (Entrevistado Dois). "Claro, não existe ser humano que não fique chocado com as notícias que tu digas, né?" (Entrevistado Nove). 0 Entrevistado Um também observou uma diferença de tratamento nas notícias seguindo linhas de classe social.

Eu acho que tem opinião. Não precisava ser dito daquela forma, tu vê que aquele discurso está sendo dito de uma maneira influenciadora para as pessoas. P: de que maneira tu percebes? Por exemplo, no caso do filho do Eike Batista e do caso de um senhor que roubou para matar a fome dos filhos. Sei lá, o caso do filho do Eike quase não repercutiu, ninguém crucificou ele. E no caso do cara que roubou pra matar a fome dos filhos vão crucificar, dizer que é ladrão, sabe? Eu vejo nisso, as vezes até por questão de distinção social. 0 filho do Eike paga cesta básica e deu, está resolvido, mas esse cara vai cumprir 20 anos de prisão. (Entrevistado Um)

Verifica-se que, entre os entrevistados, existe um consenso de nível mínimo de bem-estar onde a infração não dá condições de desvio, onde ela se torna justificável. Entre os entrevistados que apontaram esse pensamento, queixaram-se por não ver na mídia essa problematização. Reproduzimos, a seguir, a fala do Entrevistado Oito para pensarmos algumas questões: “As pessoas saem lá da vila pra ir no centro, ninguém conhece, eles pensam que as pessoas têm dinheiro lá no centro. Pode ser um pé rapado, às vezes, que nem eu, mas os caras vêm de lá pro centro pra assaltar porque lá eles acham que tem dinheiro". Percebemos uma ideia relativamente homogênea sobre o crime e a violência, que atribui a ela somente um tipo de sujeito. "Vem da vila pra assaltar" relaciona assaltantes a lugares do espaço urbano, não só reforçando a distância entre esses lugares, como atribuindo ao local uma propensão a criminosos, desconsiderando sujeitos moradores de áreas nobres da cidade, por exemplo, como agentes propensos ao crime. Podemos observar que, socialmente, o estigma do desvio recai sobre a condição social.

"P: E quanto ao infrator? Acho que as vezes eles não entrevistam a pessoa, não sabem o porquê da pessoa estar fazendo aquilo, como é que funciona o sistema de vida da pessoa pra ela estar fazendo aquilo. Sabendo o porquê o cara fez aquilo, talvez esteja acontecendo com outras pessoas e tal. Tipo: 'ah, o cara está desempregado, por isso está assaltando.' Hoje em dia com muito desemprego aumentou muito mais a violência, os assaltos, por causa disso. 0 cara que já não era muito por trabalhar e já tinha uma malandragem, já era da rua, não consegue emprego com facilidade e pensa: 'vou assaltar que é mais fácil, tem um monte de gente fazendo isso, 
não dá nada, não vou preso.' Acaba que nem quem é preso não sabe, ou como sair disso aí, ou dizer pra alguém: 'ó eu estou assaltando porque não tenho dinheiro, estou passando fome, minha família está passando fome e eu preciso'. Aí tu não sabe o porquê." (Entrevistado Oito)

0 entrevistado reconhece que existem problemas de violência que estão intimamente relacionados à condição social, como o aumento da taxa de desemprego e que, prevenindo essa situação, evita-se que outras pessoas sejam conduzidas a ações infratoras. Também, é possível verificar a dificuldade que determinados indivíduos possuem, para se ter acesso às vagas de emprego, por exemplo, "[o indivíduo que] já era da rua, não consegue emprego com facilidade." Neste contexto, a malandragem, o fato do sujeito vir das ruas, está relacionado um modo de vida das periferias que, como se observa na fala do entrevistado, carrega um estigma. Da mesma forma os reincidentes criminais.

Até menor [de idade]. Hoje em dia muito menor [de idade] acaba cometendo crime e aí tu não falas que a família não cuidou... eles tinham que abordar isso, sempre falar o porquê. Já é reincidente, já foi pra fase, já voltou. Então, são coisas que eles têm que abordar, saber o porquê, não ficar jogando as coisas, dizer: 'ó tão assaltando lá no centro, não vou no centro. E por que tão assaltando lá? Ah, não sei...' (Entrevistado Oito)

Aqui o respondente reitera as condições de vida sobre as questões criminais. Esse processo de reflexão do que envolve os sujeitos permite desconstruir certos estigmas que caracterizam o desviante, podendo, também, pensar em estratégias para redução da desigualdade e, consequentemente, a diminuição da criminalidade. Para o entrevistado, ao identificar nos telejornais o grau de periculosidade que se é noticiado pelos apresentadores, o respondente reconhece o papel legitimador da tevê na cultura do medo e a contribuição da falta de problematização no distanciamento e no medo.

Essa questão da relação criminalidade x espaço urbano (periferias) também foi apontada pelo Entrevistado Dez com relação ao telejornal:

Eu acho que, de modo geral, a periferia recebe uma pecha de violência. Assim como as favelas nas grandes cidades, as vilas na cidade, 'não lá é violento porque lá acontece tal coisa', então em Rio Grande, o BGV é tido como violento e eu vejo milhares e milhares de pessoas fazendo a sua vida ali, né? (...) Então tem a questão da droga, da drogadição do tráfico. Tem muito na periferia? Tem, mas tem na periferia e o pessoal do centro vai comprar. É o consumidor. Mas a pecha da violência fica na periferia. Então acho que isso tem muito a ver com a divulgação (Entrevistado Dez).

Apesar das visões semelhantes que apresentamos no decorrer no trabalho, que apontaram as questões de desvio próximas a linhas de classe e etnia - este último mais ligado ao cenário social, não midiático, existem também outras visões sobre a construção da imagem do telejornal. Como aponta o Entrevistado Sete:

Geralmente o policial é o bandido, porque ele deu um tiro num cara ou bateu num cara, essas coisas assim. Às vezes eles acham que a vítima tava errada de estar andando de noite sozinha. Primeiro, a gente tem o direito de ir onde quiser com liberdade. 0 ladrão eles deixam ficar muito impune, digamos assim. 0 ladrão ele não teve direito ao estudo, essas coisas. Aí eles já começam a culpar o governo; ah tá certo tem uma parte de culpa, mas não é totalmente a culpa do governo. Mas é mais em cima do policial, o policial deu um tiro num cara, o policial tá errado. Isso aí é o que eu mais 
me indigno. Se ele tentou defender ele ou alguém, deu o tiro no cara e está errado. Sempre assim.

Sendo assim, tivemos uma perspectiva bastante diferente sobre a construção da imagem do desviante no Jornal do Almoço. Percebem-se algumas correlações diferentes das opiniões apresentadas pelos demais respondentes anteriormente. É possível observar, por exemplo, que o Entrevistado Sete considera a apresentação do infrator de forma branda no telejornal. Outra observação interessante referente a esta fala é sua conexão com a posição de vítima e com a situação de roubo/furto e a menor consideração da condição de vida como um meio de influenciar o crime - bastante enfatizado pelos demais entrevistados.

Além disso, podemos ver a distinção criada entre vítima e infrator através da reivindicação de direitos fundamentais. A vítima aqui não pode ser privada do direito de ir e vir pela ação de terceiros, mas a garantia do direito à educação, exemplificado pelo entrevistado, não é considerado um fator importância fundamental, se o agente não seguiu as normas estabelecidas. Ou ainda, o quanto antes - visto que, teoricamente, o agente se tornou infrator pela ausência de assistência de seus direitos básicos, entretanto, a partir do momento em que este sujeito se torna estranho às normas estabelecidas, não mais interessa que ele não tenha acesso a condições mínimas.

Como última contribuição, salientamos a colocação do Entrevistado Dez sobre a relação da mídia com a estruturação da percepção de questões sociais. 0 respondente exemplifica, através da maneira como o ECA - Estatuto da Criança e Adolescente - é representado na mídia. Segundo explica, essa legislação é exemplo para muitos países, mas não é aplicada por uma falha em todo o sistema. Nesse caso, o entrevistado aponta que o sistema não é criticado - apenas a lei, que inviabiliza um projeto útil socialmente, por uma visão equivocada de que é o Estatuto que não é funcional para crianças e jovens. A partir dessa perspectiva, são apontados alguns impactos causados por colocações, como a do exemplo:

Então, o sistema tá todo errado. E isso não é trabalhado, isso é isolado. E tem a questão do pré-julgamento. Tá ali, foi quem fez e a defesa? Isso acaba dando também pra população que assiste que 'não, eu tenho o direito de julgar esse cara, isso tá uma vergonha, a polícia não faz nada, nós temos que fazer' e aí vem até o exagero, até linchamentos, que é uma volta da barbárie, né? Além dos telejornais que dão esses 'criminoso, criminoso, criminoso' tem o restante da programação da tevê, que é um absurdo, que tem pseudojornalistas que são pessoas que se acham no direito de julgar, inclusive incitam a violência, que é crime. Deviam ser afastados da televisão. Principalmente televisão. Esse pré-julgamento pra mim é a pior coisa que tem, que tira-se o direito de defesa e corre-se um risco muito grande de acusar inocentes, e pra mim isso é a pior falha que pode ter um sistema judiciário num país, e de comunicação igual, né? Porque caminham juntos (Entrevistado Dez).

Embora o Entrevistado Dez tenha mais condições de realizar críticas à mídia e ao Jornal do Almoço, tendo em vista sua formação base, que lhe confere um escopo teórico possível para tecer análises aprofundadas, ainda sim, ele o faz com base em suas próprias condições e contexto social, como a maioria dos entrevistados. Alguns entrevistados não percebem nenhuma construção padronizada nas

Memorare, Tubarão, v. 8, n. 1, jan./jun. 2021. ISSN: 2358-0593 
notícias e, embora estas contribuam para a formação da cultura do medo - até reconhecida por alguns próprios entrevistados, não foram colocadas pelos respondentes como construtoras da imagem do desviante. Nos demais entrevistados que apontaram essa construção, pudemos perceber que também o fizeram considerando suas próprias visões de mundo, carregando a imagem que consideram estigmatizada para a imagem do desviante para o telejornal. É importante ressaltar que seria a imagem de estigma, não propriamente de desvio, que eles observam como o desviante do telejornal. Por exemplo, o entrevistado Três considera estigmatizados os grupos negros e de classe baixa e, portanto, aponta que essa é a imagem que o telejornal adota como desviante. Já o entrevistado sete vê como desviante o negro, mal vestido e, especialmente, a pessoa que infringe normas legais - sem considerar condições de vida. Para ele, o grupo estigmatizado são os policiais e, portanto, o grupo retratado pelo telejornal como desviante.

\section{Considerações finais}

Percebe-se, neste trabalho, a violência, enquanto estrutura, e reconhece-se como parte responsável por uma situação desigual, capaz de gerar fatores como a criminalidade. Aponta-se, também, a globalização como fator que intensifica esse processo, fortalecendo uma estrutura polarizada, marcada pela condição não igualitária dos modos de vida, ainda que se proponha a uma unificação dos povos.

Através dessa polarização, reconhece-se que grupos se tornam estranhos uns aos outros e, enquanto alguns podem conviver com a própria reserva, outros grupos se tornam excluídos porque não têm as mesmas condições de se apropriar dos mecanismos utilizados por outras pessoas. Também agravado pelo processo de globalização, a nova composição das cidades e a abrangência midiática, compreende-se que existe uma fenda cultural, na relação indivíduo x cidade e indivíduo $\mathrm{x}$ indivíduo, na qual possibilita a televisão se consolidar como lugar de familiaridade entre o sujeito e o espaço. Essa mesma fenda se coloca como geradora do medo, pelas relações enfraquecidas.

Esses fatores - medo, falta de contato, familiaridade da tevê, somados, contribuem para a criação de uma cultura do medo e estão sendo fator importante para consolidar e naturalizar formas de segregação. Porém, para definir a segregação, ou seja, para que alguns indivíduos possam "proteger-se" de outros, esse sujeito considerado uma ameaça também deve se personificar. Esse é o desviante, construído de um grupo para outro. Esses grupos conseguem perceber características desviantes um no outro, acentuando suas diferenças. Diferenças, essas, que não mais conseguem conviver, porque a ausência do contato se intensifica em um processo de mão dupla: a composição os afasta, eles já não se reconhecem, o que os afasta ainda mais.

Portando, para finalizar, cabe destacar que o objetivo deste trabalho foi fazer uma breve - diante de tudo o que ainda precisa ser estudado -, reflexão sobre os pontos da cultura do medo e da construção da imagem do desviante. Para isso, realizou-se entrevistas semiestruturadas, com amostra selecionada de forma aleatória entre pessoas que assistem o Jornal do Almoço, para visualizarmos as percepções dos entrevistados sobre o assunto. Por meio das entrevistas 
realizadas com os telespectadores do Jornal do Almoço, verificamos que a tevê exerce um papel importante no cotidiano dos indivíduos e que esta se estabelece como legitimadora dos fatos ocorridos em Rio Grande. Ainda assim, notamos que existe um grande atravessamento da internet e das próprias relações interpessoais que se estabelecem nas práticas cotidianas nas formas de apropriações dos conteúdos telejornalísticos.

\section{Referências}

BAUMAN, Zygmunt. Globalização: as consequências humanas. Rio de Janeiro: Zahar, 1999.

BECKER, Howard. Outsiders. Tradução: Maria Luiza X. de A. Borges. Rio de Janeiro: Zahar, 1963. 231p.

CHAUÍ, Marilena - Ética e Violência no Brasil. In: Revista Bio\&thikos - Centro Universitário São Camilo. 2011. Disponível em: http://www.saocamilosp.br/pdf/bioethikos/89/A3.pdf. Acesso em: 23 mai. 2015

CHAUÍ, Marilena. Convite à filosofia. 13 ed. São Paulo: Ática, 2008. 310 p.

CHAUÍ, Marilena. Democracia e sociedade autoritária. Palestra proferida pela Professora Marilena Chauí, em Goiânia, no dia 14 de março de 2013, no Espaço Oscar Niemayer, no evento Café de Ideias. Disponível em: http://h200137217135.ufg.br/index.php/ci/article/viewFile/24574/14151 Acesso em: 12 jul. 2015.

COUTO, Mia. Conferência de Estoril 2011. 2011. Disponível em: https://www.youtube.com/watch?v=jACccaTogxE. Acesso em: 14 abr. 2015

ESCOSTEGUY, Carolina; SIFUENTES Lílian: As relações de classe e gênero no contexto de práticas orientadas pela mídia: apontamentos teóricos. In: Revista da Associação Nacional dos Programas de Pós-Graduação em Comunicação | Ecompós, Brasília, v.14, n.2, maio/ago. 2011. Disponível em: http://www.compos.org.br/seer/index.php/ecompos/article/viewFile/655/523. Acesso em: 27 out. 2015.

GUEDIN Giorgio Rosso; DA CRUZ Fábio Souza. Informalidade e Credibilidade no Jornal do Almoço do Rio Grande do Sul: Um Estudo de Recepção. In: Anais Intercom Sociedade Brasileira de Estudos Interdisciplinares da Comunicação XV Congresso de Ciências da Comunicação na Região Sul, 2014, Palhoça. Diponível em: http://www.portalintercom.org.br/anais/sul2014/lista_area_IJ01.htm. Acesso em: 19 jun. 2015.

GIL, Antonio Carlos. Métodos e técnicas de pesquisa social. 6. ed. São Paulo : Atlas, 2008.

KELLNER, Douglas. A Cultura da mídia - estudos culturais: identidade e política entre o moderno e o pós moderno. Bauru, SP: EDUSC, 2001.

MANZINI, E. J. A entrevista na pesquisa social. Didática. São Paulo, v. 26/27, p. 149-158, $1990 / 1991$.

MARCONI, Marina; LAKATOS Eva Maria. Fundamentos de metodologia científica. 5. ed. São Paulo: Atlas 2003. 
MARTÍN-BARBERO, Jesus. Comunicação e Cidade: entre Meios e Medos. In: Novos Olhares: Revista de Estudos Sobre Práticas de Recepção a Produtos Midiáticos, 1998, São Paulo. Disponível em:

http://www.revistas.usp.br/novosolhares/article/view/51305. Acesso em: 17 jun. 2015.

MARTÍN-BARBERO, Jesus. Ofício de cartógrafo. São Paulo: Edições Loyola, 2004. p. 274303.

OROZCO, Guillermo. La Investigación en Comunicación desde la perspectiva Cualitativa.

Ediciones de Periodismo y Comunicación Social, Capitulo IV, La

Perspectiva Cualitativa, 1998, p. 67-93. Disponível em:

https://casamdp.files.wordpress.com/2013/08/orozco-cap-iv.pdf. Acesso em: 10 nov. 2015

PASTANA, Débora Regina. Cultura do Medo e Democracia: Um Paradoxo Brasileiro. In:

Revista Mediações. Londrina, 2005, v. 10, n. 2 - Disponível em:

http://www.uel.br/revistas/uel/index.php/mediacoes/article/viewArticle/2 172. Acesso em: 3 nov. 2014

RONDELLI, Elizabeth. Imagens da violência: práticas discursivas. Tempo Social; Rev. Sociol. USP, S. Paulo, 10(2): 145-157, outubro de 1998. Disponível em: http://www.revistas.usp.br/ts/article/view/86785/89787. Acesso em: 20 out. 2015

SILVA, Anderson Luís. Afinal, o que a classe média que ver no Jornal do Almoço?: Um estudo de recepção junto aos telespectadores gaúchos. 2013, 204 p.

Dissertação (Mestrado em Comunicação Social) - Pontifícia Universidade Católica do Rio Grande do Sul, Porto Alegre, 2013. Disponível em: http://repositorio.pucrs.br/dspace/handle/10923/2188. Acesso em: 26 out. 2015

VIZEU, Aurico: Telejornalismo: cotidiano e lugar de segurança. Estudos em Jornalismo e Mídia. Vol. III No 1 - 1o semestre de 2006. Disponível em: https://periodicos.ufsc.br/index.php/jornalismo/article/view/2246/1950. Acesso em: 26 out. 2015.

Artigo enviado em: 03/07/2020. Aprovado em: 28/04/2021. 